\title{
Experimental model of Achilles tendon injury in rats ${ }^{1}$
}

\author{
Flavia Emi Akamatsu', Samir Omar Saleh", Walcy Rosolia Teodoro ${ }^{\mathrm{III}}$, Alexandre Queiroz da Silva ${ }^{\mathrm{IV}}$, Carlos Augusto Real \\ Martinez $^{\mathrm{V}}$, Ricardo Jordão Duarte ${ }^{\mathrm{VI}}$, Mauro Figueiredo Carvalho de Andrade ${ }^{\mathrm{VII}}$, Alfredo Luiz Jacomo ${ }^{\mathrm{VII}}$
}

DOI: http://dx.doi.org/10.1590/S0102-86502014000700002

${ }^{\mathrm{I}} \mathrm{PhD}$, Assistant Professor, Division of Human Structural Topography, Department of Surgery, Laboratory of Medical Research, Faculty of Medicine, University of Sao Paulo (FMUSP), Brazil. Conception, design, intellectual and scientific content of the study, English version.

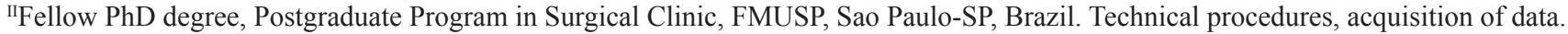

${ }^{\text {III }} \mathrm{PhD}$, Assistant Professor, Department of Internal Medicine, Laboratory of Medical Research, FMUSP, Sao Paulo-SP, Brazil. Acquisition and interpretation of data.

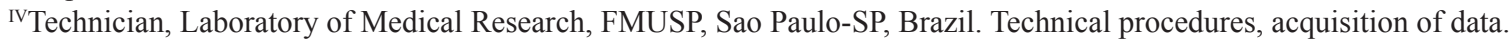

${ }^{v} \mathrm{PhD}$, Associate Professor, Postgraduate Program in Health Sciences, Medical School, Sao Francisco University (USF), Bragança Paulista-SP, Brazil. Interpretation of data, manuscript writing, critical revision.

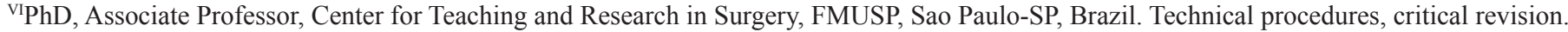

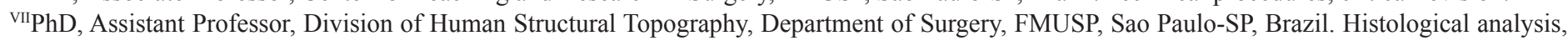
interpretation of data.

${ }^{\mathrm{VIII}} \mathrm{PhD}$, Associate Professor, Division of Human Structural Topography, Department of Surgery, Medical Research Laboratory, FMUSP, Sao Paulo-SP Brazil. Intellectual and scientific content of the study, critical revision.

\section{ABSTRACT}

PURPOSE: To describe an effective experimental model to study the Achilles tendon healing.

METHODS: Forty male Rattus norvegicus albinus, Wistar lineage adult male weighing 250 to $300 \mathrm{~g}$ were used for this experiment and thirty were surgically submitted to bilateral partial transverse section of the Achilles tendon. The right tendon was treated with radio waves (RF) whereas the left tendon served as control. On the third postoperative day, the rats were divided into four experimental groups consisting of ten rats each which were treated with monopolar RF adjusted to $650 \mathrm{kHz}$ and $2 \mathrm{w}$, for two minutes twice a week and a group of normal animals without any intervention, until they were sacrificed on the $7^{\text {th }}, 14^{\text {th }}$ and $28^{\text {th }}$ days, respectively. Tendons were weighed and collagen quantification was evaluated by hydroxyprolin content.

RESULTS: Significant reduction in collagen content on day 7, 14 and 28 was related to control experiment to normal tendon (7 days, $\mathrm{p}<0.01 ; 14$ e 28 days, $\mathrm{p}<0.05)$.

CONCLUSION: The experimental model has been effective and available to be used to study Achilles tendon healing.

Key words: Models, Animal. Achilles Tendon. Collagen Type I. Hydroxyproline. Radio Waves. Rats. 


\section{Introduction}

Injuries to tendons are among the most common injuries to the body. They include complete tendon ruptures that occur from a single overload event as well as the less dramatic but more common incomplete injuries such as tendinitis. These injuries are not only responsible for large health care costs, but they also result in lost work time and individual morbidity ${ }^{1}$. Although, there are medical treatments for most of these conditions, continuing efforts need to be made to improve the effectiveness of the treatments and accelerate recovery. In the past, most of these efforts have been directed at improving surgical, pharmacological and rehabilitative techniques. Despite many improvements in these techniques, there remain significant limitations in our management of these conditions.

In order to determine if a proposed animal tendon injury model is appropriate a number of conditions must be met. The correct anatomic structure must be modeled and the desired experimental condition must be simulated. Complete and incomplete injuries are modeled differently. Another important factor to determine at the outset is the outcome measure desired to assess the effectiveness of the technique being tested. Since the primary function of tendons is to transfer loads, injuries to these structures result in the interruption of load transfer and loss of function.

There are several pathologic conditions more common that occur to tendons and most appropriate to model as partial and complete tissue injuries and clinically these injuries often do not heal properly leading to significant morbidity and often require reconstructive surgery. These conditions have been simulated through partial lesion, partial tissue laceration, tendinitis, tendinosis, transecctions, hole punction, incisional wound, dropping, total transection, longitudinal lesion and hemisecction on Achilles tendon $^{2-12}$. Techniques to prevent injury or accelerate healing after injury can be tested in these models. Overall, there are major differences in the modeling of the different types of soft tissue injuries. As a result, each type of soft tissue condition (partial injuries, complete injuries) requires different modeling approaches. Tendon repair involves a complex orchestrated series of physiological events that include protein synthesis, cell migration, and degradation of the extracellular matrix, particularly collagen ${ }^{13}$.

An appropriate animal model should be available to study the tendon healing process. We describe a protocol for Achilles tendon injury in rats showing its effectiveness by quantifying 4-hydroxyprolina on phases of tendon regeneration and using the contralateral paw as control.

\section{Methods}

This study was approved by the Ethics Committee for the Analysis of Research Projects (CAPPesq) Protocol 164/10. The study followed the principles complied with Federal Law No. 11.794, of October 8, 2008, and Decree No. 6,689, of July 15, 2009 that regulated the Law 11.794. All animals received human care in compliance with the experimental protocols of the Ethical Principles in Animal Experiments adopted by the Brazilian Association of Animal Testing (COBEA).

Forty Adult male Rattus norvegicus albinus, Wistar weighing 250 to $300 \mathrm{~g}$ were housed in the São Paulo University School of Medicine Barrier. Animals were housed five per cage were given food and purified tap water ad libitum. Ten animals were used for normal group, normal right Achilles tendon (NRT) and normal left Achilles tendon (NLT), without surgery and thirty animals were used for surgery group (S). The animals of surgery group were operated in CEPEC (Center for Study and Research in Surgery, in the Department of Urology, Faculty of Medicine, University of Sao Paulo) (Figure 1A). It was used for experiment the right Achilles tendon (SRT) and as control the left one (SLT) of the same animals of surgery group. Rats were placed under general anesthesia with $4 \%$ isoflurane and maintained anesthetized by mask with inspired fraction of 1.5-3\% isoflurane (Figure 1B). After anesthesia, the distal portions of the right and left legs of the animal shall be subjected to disinfection with chlorhexidine gluconate solution $10 \mathrm{mg}$ and shaved.

Animals were placed in a sterile field on a heated surgery table and covered with a sterile surgical drape. The skin was cut longitudinally, lateral and $0.5 \mathrm{~cm}$ from the calcaneal insertion lateral to the tendon, both the peritendon and tendon exposed.

The animals were surgically submitted to bilateral partial transverse section of the Achilles tendon. The injury in this animal model was represented by dissection and transverse hemisection by $\mathrm{N}^{\mathrm{o}} 15$ scalpel blade perpendicular to the collagen fibers, $2.5 \mathrm{~mm}$ from Achilles insertion on the lateral side of Achilles tendon (Figure 1C-F).

We took care to separate the flexor halluces longus which is next to the Achilles tendon medially. After transection, the skin was closed by a continuous suture with Polipropilene 6-0 (Figure $1 \mathrm{G}, \mathrm{H})$. After surgery, the rats were kept warm until they recover the consciousness. Analgesics were administered (paracetamol $200 \mathrm{mg} / \mathrm{kg}$ ) orally every 24 hours for three days. The rats were left without cast immobilization. During the time they were kept housed, they were acclimatized to $12 \mathrm{~h}$ light-dark cycles. 

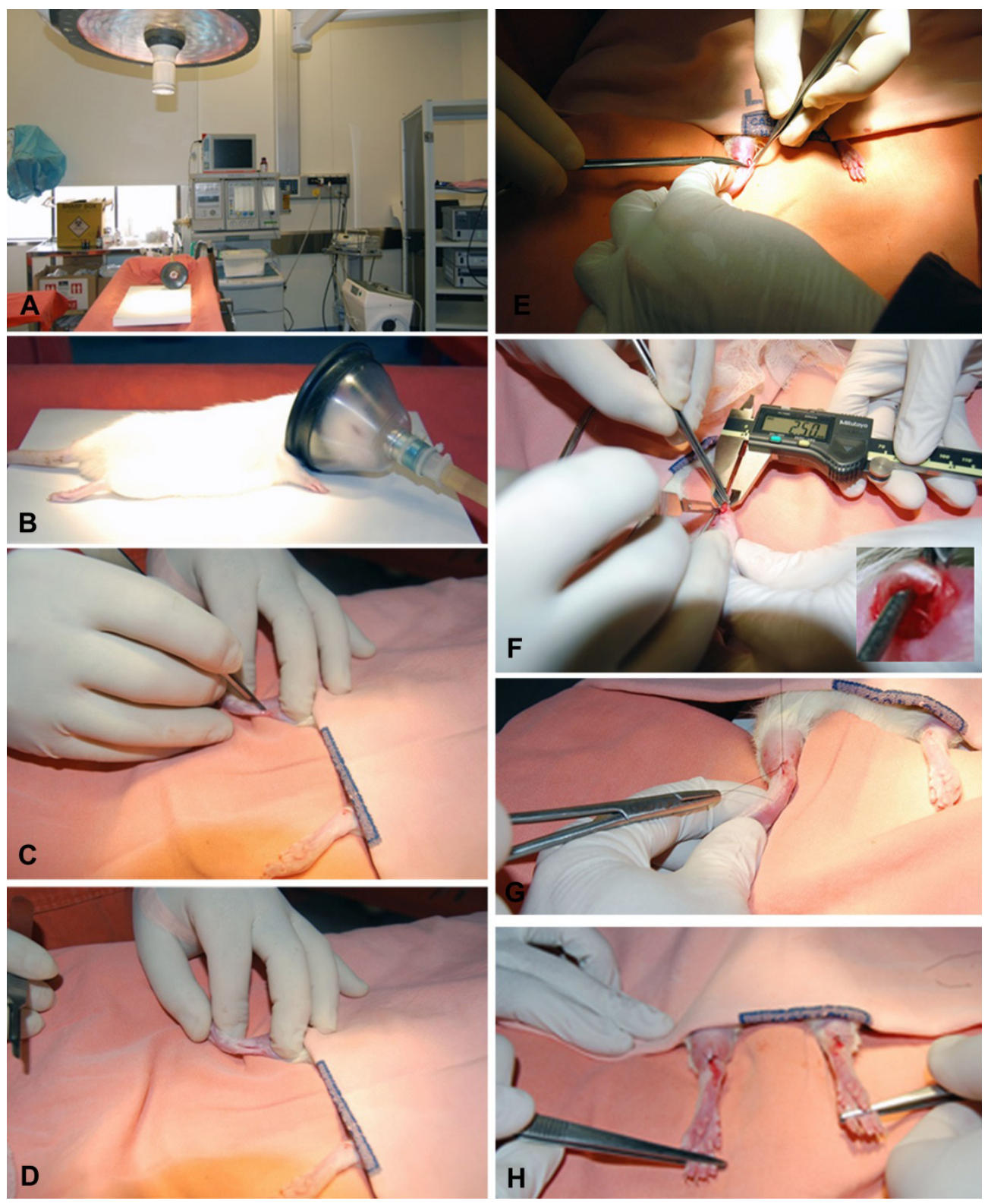

FIGURE 1 - A. Center for Teaching and Research in Surgery (CEPEC) of University of Sao Paulo Medical School. B. Rat before surgery. C, D. The skin was cut longitudinally, lateral and $0,5 \mathrm{~cm}$ from the calcaneal insertion lateral to the tendon, both the peritendon and tendon exposed. E. Dissecting the tendon. F. The hemisection was made with a no. 15 scalpel blade perpendicular to the collagen fibers, $2.5 \mathrm{~mm}$ from the calcaneous insertion, on lateral side of the tendon. G, H. The skin was closed by a continuous suture with Polipropilene 6-0.

To find out if the lesion was effective we measure the hydroxyproline content at seven, fourteen and twenty eight days and compared the control and contralateral injured tendons to a normal one. On the third postoperative day, the rats were divided into four experimental groups in which one group with normal tendon and the others three groups treated with monopolar RF (Tonederm ${ }^{\mathrm{TM}}$ ) adjusted to $650 \mathrm{kHz}$ and $2 \mathrm{w}$, for two minutes twice a week, until they were sacrificed on the $7^{\text {th }}, 14^{\text {th }}$ and $28^{\text {th }}$ days.

\section{Euthanasia}

After each period of treatment the animals were euthanized using $\mathrm{CO}_{2}$ (Carbon Dioxide). The animals were placed in chambers previously filled with pure gas, or preferably, gas added with $30 \%$ oxygen to reduce distress caused by hypoxia. As $\mathrm{CO}_{2}$ is twice as heavy as the air it sits at the bottom of the chamber. Therefore, the chamber opening should be on the top. $\mathrm{CO}_{2}$ is a deadly gas because it causes depression in the central neural system. The animals should be kept in the chamber for 10 minutes so that their death will be confirmed ${ }^{14}$. Achilles tendons were collected through their dissection with the animal in the prone position following the procedures of the methodology used. Specimens were intended for quantification of collagen. 


\section{Collagen quantification-4- hydroxyproline}

The collagen content was determined by measuring the hydroxyproline content according Bergman and Loxley ${ }^{15}$. Dry weights of lyophilized samples ( $\mathrm{n}=40$ for each time point) were measured and transferred to tube,culture, $13 \times 100 \mathrm{~mm}$ (Corning, NY14831) containing $5 \mathrm{ml}$ of $6 \mathrm{~N}$ HCL. In separate tubes, 0 (blank) and 4, 6, 8, 10 and $12 \mu \mathrm{g}$ of the hydroxyproline standard (Sigma) were prepared to establish a standard curve for each experiment. Samples were hydrolyzed at $100^{\circ} \mathrm{C}$ for 22 hours and then oxidized by adding chloramine- $\mathrm{T}$ reagent and incubating at room temperature for $25 \mathrm{~min}$. After oxidation, a chromophore was developed by adding Ehrlich's reagents to each sample and incubating at $65^{\circ} \mathrm{C}$ for $20 \mathrm{~min}$. The absorbance of each standard and the samples was measured at $560 \mathrm{~nm}$ by spectrometry. The collagen content was calculated by multiplying the hydroxyproline content by 7.0 as previously described ${ }^{16}$. Collagen production for each sample was determined by dividing the total collagen content by the total weight of each sample.

\section{Statistical analysis}

Data were analyzed statistically and values are expressed by median. Normality of the variables was assessed. In order to assess whether there was any difference it was decided by nonparametric Mann-Whitney U test. Significance was accepted at $\mathrm{p}<0.05$. Data were analyzes using the statistical package SPSS17.0 (Chicago, IL).

\section{Results}

The amount of hydroxyproline was significantly lower in injured tendons compared to normal control tendons at the study ( 7 days, $\mathrm{p}<0.01,14$ and 28 days, $\mathrm{p}<0.05$ ) Tables 1 and 2 .

TABLE 1 - Comparison of hydroxyproline content between Normal Left Tendon (NLT) and Surgery Left Tendon (SLT).

\begin{tabular}{ccccccccc}
\hline \multicolumn{9}{c}{ NLT } \\
\hline Days & Median & Minimum & Maximum & Median & Minimum & Maximum & p \\
7 & 83.07 & 69.04 & 111 & 56.07 & 34.29 & 70.80 & $0.0003^{* *}$ \\
14 & 83.07 & 69.04 & 111 & 63.62 & 40.88 & 143.65 & $0.0114^{*}$ \\
28 & 83.07 & 69.04 & 111 & 73.77 & 61.90 & 81.94 & $0.0218^{*}$ \\
\hline
\end{tabular}

NLT $=$ Normal Left Tendon; SRT $=$ Surgical Left Tendon; * = significant at $5 \% ; * *=$ significant at $1 \%$

TABLE 2 - Comparison of hydroxyproline content between Normal Right Tendon (NRT) and Surgery Right Tendon (SRT).

\begin{tabular}{ccccccccc}
\hline & \multicolumn{9}{c}{ SRT } \\
\hline Days & Median & Minimum & Maximum & Median & Minimum & Maximum & p \\
7 & 78.50 & 50.85 & 88.73 & 57.66 & 33.13 & $0.0003^{* *}$ \\
14 & 78.50 & 50.85 & 88.73 & 63.56 & 48.07 & 83.73 & $0.0114^{*}$ \\
28 & 78.50 & 50.85 & 88.73 & 69.83 & 57.25 & 79.43 & $0.0218^{*}$ \\
\hline
\end{tabular}

$\mathrm{NRT}=$ Normal Right Tendon; SRT $=$ Surgical Left Tendon; $*$ = significant at $5 \% ; * *=$ significant at $1 \%$ 


\section{Discussion}

Tendon healing occurs in three overlapping phases. In the initial inflammatory phase, erythrocytes and inflammatory cells, particularly neutrophils, enter the site of injury. In the first 24 hours, monocytes and macrophages predominate, and phagocytosis of necrotic materials occurs. Vasoactive and chemotactic factors are released with increased vascular permeability, initiation of angiogenesis, stimulation of tenocyte proliferation, and recruitment of more inflammatory cells ${ }^{17}$. Tenocytes gradually migrate to the wound, and type III collagen synthesis is initiated. After a few days, the remodeling stage begins which the synthesis of type III collagen peaks during this stage, which lasts for a few weeks. In the approximately six weeks, the modeling stage commences. During this stage, the healing tissue is resized and reshaped. A corresponding decrease in cellularity, collagen and glycosaminoglycan synthesis occurs ${ }^{16}$.

Especially at the initial inflammatory phase, the hydroxyproline content of model experiment were less than the normal tendon and this is probably because of phagocytosis of necrotic materials. Collagen typing experiments, using material from normal and ruptured Achilles tendons, demonstrated that ruptured tendons contained reduced quantities of type I Collagen as well as a significant proportion of type III collagen and this justify less amount of hydroxyproline content in our work ${ }^{13,18}$.

The presence of type III collagen likely accounts for the decreased resistance of tendon to tensile forces, and may therefore predispose the tendon to spontaneous rupture ${ }^{19}$.

Type I collagen is the major component of normal tendon, greatly contributing to the strength of the tissue ${ }^{19,20}$. As it can be observed, the content of hydroxyproline used as an indicator of collagen content with the injury was significantly lower than normal tendons at all-time points, thus confirming the effectiveness of the experimental injury. It hasn't been evaluated in this work the collagen content of tendon subjected to radiofrequency because this was for other work, so we evaluated only normal tendon compared with the control experiment, which was left tendon. Over time 28 days is suggested attempt to approach collagen recovering the injured tendon to normal.

Although the tensile strength of the healing tendon improves over time, it does not reach the levels of uninjured, normal tissue ${ }^{13}$. This model can be used to study tendon regeneration. It's important to state that tendon recovery is still controversial in the therapeutic resource literature.

\section{Conclusion}

The proposed experimental model has been effective and available to be used to study Achilles tendon healing.

\section{References}

1. Dunning KK, Davis KG, Cook C, Kotowski SE, Hamrick C, Jewell G, Lockey J. Costs by industry and diagnosis among musculoskeletal claims in a state workers compensation system: 1999-2004. Am J Ind Med. 2010 Mar;53(3):276-84. doi: 10.1002/ajim.20774.

2. Postachini F, De Martino C. Regeneration of rabbit calcaneal tendon maturation of collagen and elastic fibers following partial tenotomy. Connect Tissue Res. 1980;8(1):41-7. PubMed PMID: 6450662.

3. Frieder S, Weisberg J, Fleming B, Stanek A. A Pilot study: the therapeutic effect of ultrasound following partial rupture of achilles tendons in male rats. J Orthop Sports Phys Ther. 1988;10(2):39-46. PubMed PMID: 18796976.

4. Hitchcock TF, Candel AG, Light TR, Blevens AD. New technique for producing uniform partial lacerations of tendons. J Orthop Res. 1989;7(3):451-5. PubMed PMID: 2703938.

5. Backman C, Boquist L, Fridén J, Lorentzon R, Toolanen G. Chronic achilles paratenonitis with tendinosis: an experimental model in the rabbit. J Orthop Res. 1990 Jul;8(4):541-7. PubMed PMID: 2355294.

6. Murrell GA, Lilly EG, Davies H, Best TM, Goldner RD, Seaber AV. The Achilles functional index. J Orthop Res. 1992 May;10(3):398404. PubMed PMID: 1569503.

7. Demir H, Menku P, Kirnap M, Calis M, Ikizceli I. Comparison of the effects of laser, ultrasound, and combined laser + ultrasound treatments in experimental tendon healing. Lasers Surg Med. 2004;35(1):84-9. PubMed PMID: 15278933.

8. Ehrlich HP, Lambert PA, Saggers GC, Myers RL, Hauck RM. Dynamic changes appearing in collagen fibers during intrinsic tendon repair. Ann Plast Surg. 2005 Feb;54(2):201-6. PubMed PMID: 15655474.

9. Neves MA, Pinfildi CE, Wood VT, Gobbato RC, da Silva FM, Parizotto NA, Hochman B, Ferreira LM. Different power settings of LLLT on the repair of the calcaneal tendon. Photomed Laser Surg. 2011 Oct;29(10):663-8. doi: 10.1089/pho.2010.2919.

10. Kosaka T, Masaoka T, Yamamoto K. Possible molecular mechanism of promotion of repair of acute Achilles tendon rupture by low intensity-pulsed ultrasound treatment in a rat model. West Indian Med J. 2011 Jun;60(3):263-8. PubMed PMID: 22224336.

11. Sasaki K, Yamamoto N, Kiyosawa T, Sekido M. The role of collagen arrangement change during tendon healing demonstrated by scanning electron microscopy. J Electron Microsc (Tokyo). 2012;61(5):327-34. doi: 10.1093/jmicro/dfs057.

12. Tibor LM, Leek BT, Chase DC, Healey RM, Linn MS, Tasto JP, Amiel D. A biomechanical assessment of tendon repair after radiofrequency treatment. Am J Orthop (Belle Mead NJ). 2012 Sep;41(9): E115-21. PubMed PMID: 23365813.

13. Lin TW, Cardenas L, Soslowsky LJ. Biomechanics of tendon injury and repair. J Biomech. 2004 Jun;37(6):865-77. PubMed PMID: 15111074.

14. Nolen RS. Revision process begins for AVMA euthanasia guidelines. J Am Vet Med Assoc. 2009 Aug 1;235(3):246-7. PubMed PMID: 19725198.

15. Bergman I, Loxley R. Lung tissue hydrolysates: studies of the optimum conditions for the spectrophotometric determination of hydroxyproline. Analyst. 1969 Jul;94(120):575-84. PubMed PMID: 5804368.

16. Samuel, CS. Determination of collagen content, concentration, and sub-types in kidney tissue. Methods Mol Biol. 2009;466:223-35. doi: 10.1007/978-1-59745-352-3_16.

17. Murphy PG, Loitz BJ, Frank CB, Hart DA. Influence of exogenous growth factors on the synthesis and secretion of collagen types I and 
Akamatsu FE et al.

III by explants of normal and healing rabbit ligaments. Biochem Cell Biol. 1994 Sep-Oct;72(9-10):403-9. Pub Med PMID: 7605612.

18. Ippolito E, Natali PG, Postacchini F, Accinni L, De Martino C. Morphological, immunochemical, and biochemical study of rabbit Achilles tendon at various ages. J Bone Joint Surg Am. 1980; 62(4):583-98. PubMed PMID: 6991502.

19. Józsa L, Bálint BJ, Réffy A, Demel Z. Fine structural alterations of collagen fibers in degenerative tendinopathy. Arch Orthop Trauma Surg. 1984;103(1):47-51. PubMed PMID: 6466064.

20. Waterston SW, Maffulli N, Ewen SW. Subcutaneous rupture of the Achilles tendon: basic science and aspects of clinical practice. Br J Sports Med. 1997 Dec;31(4):285-98. PubMed PMID: 9429005.

\section{Correspondence:}

Carlos Augusto Real Martinez

Laboratório de Investigação Médica

Universidade São Francisco

Avenida São Francisco de Assis, 218

12916-350 Bragança Paulista - SP Brasil

carmartinez@uol.com.br

Received: Feb 18, 2014

Review: April 16, 2014

Accepted: May 14, 2014

Conflict of interest: none

Financial source: none

${ }^{1}$ Research performed at Laboratory of Medical Research-02, Division of Human Structural Topography, Faculty of Medicine of University of Sao Paulo (FMUSP), Brazil. 